\title{
Sexo para quase todos: a prostituição feminina na Vila Mimosa * \\ Elisiane Pasini**
}

Resumo

Este artigo tem como base de análise uma pesquisa etnográfica localizada numa antiga zona de prostituição feminina fechada na cidade do Rio de Janeiro - a Vila Mimosa. Aqui apresento a problemática de que espaços criados em função do consumo de sexo local também estão sendo voltados para o encontro entre trabalhadoras/es do sexo locais e estrangeiros. A discussão centrase em como este macro espaço de prostituição feminina transforma-se num palco de conflito quando se torna um mercado sexual também utilizado pelos estrangeiros.

Palavras-chave: Prostituição Feminina, Turismo, Relações de Gênero, Rio de J aneiro, Vila Mimosa.

\footnotetext{
* Recebido para publicação em julho de 2005, aprovado em setembro de 2005. Agradeço o apoio e o incentivo constante de Adriana Piscitelli.

** Coordenadora do Programa de Formação de Jovens Multiplicadoras de Cidadania (J MC's) da ONG Themis, Porto Alegre-RS. lispasini@ hotmail.com 
Prostituição feminina na Vila Mimosa

Sex for Almost All:

Female Prostitution in Vila Mimosa

Abstract

This article is based on ethnographic research conducted in an old zone of closed female prostitution in Rio de J aneiro - Vila Mimosa. I argue that the spaces created for the consumption of local sex are being used also for encounters between local sex laborers and foreigners. The discussion rises the question that this macrospace of female prostitution is becoming a stage for conflict when it becomes also a sex market used by foreigners.

Key Words: Female Prostitution, Tourism, Gender Relations,

Rio de Janeiro, Vila Mimosa. 
Elisiane Pasini

Cheguei na Vila, como de costume, pela rua onde há mais esgotos abertos, mas, ao mesmo tempo, parece ser mais segura em razão do movimento dos guardadores de carro. Assim que dou os primeiros passos na rua Sotero dos Reis vejo dois homens parados em frente de uma casa ${ }^{1}$ de prostituição - a qual, naquele momento, dei pouca atenção -, entretanto, reparei que os homens falavam em inglês. Os homens eram altos, brancos, cabelos claros, lisos e vestiam bermudas e camisetas coloridas. Logo imaginei que se tratava de estrangeiros. Curiosa, perguntei para Cleuza ${ }^{2}$ sobre os estrangeiros na Vila Mimosa, até por que lembrei que alguns meses atrás ela contou que um gringo ${ }^{3}$ havia comprado uma casa de prostituição em sociedade com um dono de casa já estabelecido na zona. Esse gringo de quem ela falara é um alemão, ex-freqüentador da Vila Mimosa e que demonstrava ter mega planos para o local. Cleuza contou que o tal gringo estava trazendo problemas para a Associação, primeiro, porque ele abriu a tal casa sem a permissão da mesma, o que a colocara num lugar de desprestígio em relação aos outros proprietários, já que é regra todos os comércios pedirem permissão à Associação para funcionar. Além disto, Cleuza argumentara que 0 estabelecimento destoava em relação aos outros - era mais equipado, bem arrumado e com mulheres mais sofisticadas - e isso estava causando constrangimento e confronto entre os proprietários.

A literatura sobre turismo sexual aponta para o fato de que essa problemática se intersecta com a prostituição e mostra como em diversas cidades do Brasil há espaços voltados

1 Os informantes se referem aos estabelecimentos de prostituição pelo termo "casa". Como um termo êmico, algumas vezes, será aqui utilizado para me referir aos estabelecimentos de prostituição.

2 Os nomes das pessoas foram trocados. Cleuza é dona de dois estabelecimentos de prostituição, participante da Associação da Vila Mimosa e foi a principal informante da pesquisa.

3 As palavras em itálico indicam que elas são assim utilizadas pelo grupo estudado, as chamadas palavras êmicas. 
Prostituição feminina na Vila Mimosa

predominantemente para o encontro entre trabalhadoras/es do sexo locais e estrangeiros. ${ }^{4}$ No entanto, os turistas sexuais também circulam por espaços criados em função do consumo de sexo local. N este texto trato de um desses espaços localizados no Rio de Janeiro, a Vila Mimosa, mostrando sua organização, seus personagens, conflitos, significados. Em outros termos, mostro como um macro espaço de prostituição feminina criado para o mercado de sexo local também é utilizado pelos estrangeiros.

\section{Conhecendo a Vila Mimosa}

Vila Mimosa é uma tradicional zona fechada de prostituição feminina localizada no centro do Rio de J aneiro, na qual realizei 0 trabalho de campo base da minha tese de doutoramento. ${ }^{5}$ Ela se constitui a partir de uma construção social e comercial, em que há uma configuração de estabelecimentos comerciais dos mais variados que vai além da venda de relações sexuais. Trata-se de um agrupamento de estabelecimentos localizados num mesmo espaço (ruas) e ligados pela atividade da prostituição.

Apesar de ter o nome de vila ${ }^{6}$, seu começo se deu em um grande galpão, com cerca de 2500 metros quadrados - um prédio construído em forma de um quadrado -, onde a parte frontal é

\footnotetext{
${ }^{4}$ Ver maiores detalhes em PISCITELLI, Adriana. Relações transnacionais, prostituição e "namoros" de verão: gênero e sexualidade no contexto do turismo sexual internacional em Fortaleza. Relatório regular de pesquisa - FAPESP, dezembro, 2001.

${ }^{5}$ A tese é um estudo antropológico sobre convenções de masculinidade e feminilidade no campo circunscrito da Vila Mimosa. Agradeço a orientação dedicada de Mariza Corrêa. PASINI, Elisiane. Homens da Vila: Um Estudo sobre Relações de Gênero num universo de Prostituição Feminina. Tese de Doutorado em Ciências Sociais, IFCH/Unicamp, Campinas-SP, 2005.

${ }^{6}$ A Vila é assim chamada porque na transferência da Zona do Mangue para um novo lugar, compraram moradias que se localizavam em um bairro que assim se chamava. A zona ficou conhecida com o mesmo nome e, na transferência daquele lugar para o atual, o nome permaneceu.
} 
aberta e de frente para a rua principal (Sotero dos Reis). ${ }^{7}$ Nas outras três linhas do quadrado e na sua parte central há estabelecimentos de prostituição. A passagem entre os dois lados desse quadrado é calçada, estreita e coberta. As duas entradas do galpão são identificadas pelos toldos amarelos e azuis colocados em cima das varandas dos estabelecimentos junto à rua principal. Os bares localizam-se na parte de baixo e os quartos, para a realização dos programas, no segundo andar. Parece uma galeria comercial, em que uma loja estaria ao lado da outra, contudo, trata-se aqui de bares. Nesta espécie de corredor, o comércio é intenso. Há vendedores informais que expõem suas mercadorias no chão, na janela de um estabelecimento, outros perambulam pelas ruas. Os vendedores informais vendem diferentes produtos: sucos, doces, salgados (coxinhas, esfihas, sanduíches), roupas (lingeries, biquínis, tops), cosméticos (batom, sombra, desodorante, perfume, cremes), incensos, bijuterias, entre outros.

A Rua Sotero dos Reis é extremamente estreita e sem asfalto. É comum haver uma fila de carros estacionados de um dos lados da rua, o que dificulta a circulação dos carros que transitam na rua, apesar disso, sempre há um trânsito intenso de carros e caminhões. Além dos carros de passeio, também há carros dos taxistas (há um ponto na rua), dos lixeiros, dos carteiros, dos policiais, dos caminhões com produtos para descarregar (bebidas, alimentos) ou da transportadora que se

\footnotetext{
${ }^{7}$ Com o passar do tempo, os negócios de prostituição e aqueles que sobrevivem em função da prostituição começaram a tomar conta de toda a região. Atualmente, além desse grande galpão principal, a Vila Mimosa ocupa toda a extensão da Rua Sotero dos Reis, cerca de três grandes quarteirões. Nas ruas do entorno localizam-se moradias (a maioria deve ter no máximo cinco cômodos, de tijolos e/ou de madeira e com a pintura envelhecida), uma transportadora, frigorífico, garagem de ônibus, oficinas mecânicas, madeireiras, depósitos de bebidas, galpões abandonados, ferro-velho, lava-jato de carros, uma pensão, uma pequena igreja (nunca a vi aberta) e alguns bares (a Rua Ceará - que termina na Rua Sotero dos Reis - é formada por diversos bares nos quais a clientela privilegiada é de motoqueiros) que não são especializados em prostituição.
} 
Prostituição feminina na Vila Mimosa

localiza ali perto. Na rua também há trânsito de pedestres: prostitutas que querem seduzir os homens que passam a pé ou de carro, homens e mulheres que utilizam o acostamento da rua para se encontrar com outras pessoas e permanecem ali bebendo e conversando, pessoas que circulam e passeiam.

Do outro lado da rua, há em torno de oito ou dez antigas moradias; todas grandes e de alvenaria. Para abrigar a atividade de prostituição, as moradias foram reestruturadas, algumas delas foram divididas em dois, três ou mais estabelecimentos, outras têm mais um andar, um puxado, com escadas para fora do prédio. Na maioria das vezes, essas moradias foram re-arranjadas para sua nova utilidade de forma que parece não ter cuidado com a segurança do prédio - há uma imensa quantidade de fios de energia elétrica sempre à mostra, tijolos jogados ao chão, construções caindo. Isto sem contar a mudança constante no cenário: no puxado ora há uma geladeira e um homem vendendo bebidas, ora há um fogareiro e uma panela onde um homem frita e vende pastéis; num momento um trailer ocupa a calçada, em outro há dois, em outro nenhum. No outro lado da rua, também há barracas, trailers, carrinhos em cima das calçadas, em frente dos estabelecimentos de prostituição.

Costumava freqüentar a Vila Mimosa durante os dias da semana e, na maioria das vezes, durante o período da tarde. Como na Vila quase todos os estabelecimentos funcionam 24 horas (apenas as barracas, as tendas e os trailers que vendem refeições e bebidas funcionam a partir das 15/16 horas) era praticamente impossível encontrá-la vazia. 0 movimento à noite é maior quando comparado com horários diurnos; a partir das 17 horas não é possível transitar tranqüilamente pelas ruas da Vila Mimosa, principalmente na sexta-feira. Mesmo durante o dia o movimento é intenso, principalmente no sábado, que parece tão movimentado quanto uma noite de outro dia qualquer da semana. A maioria dos homens com quem conversei nas tardes de sábado dizia que saíam dos seus empregos e iam diretamente para a Vila. 
A Associação dos Moradores do Condomínio e Amigos da Vila Mimosa (AMOCAVIM) ${ }^{8}$ afirma que nas noites de sexta-feira e de sábado há cerca de 4.500 pessoas (em torno de 3.000 homens e 1.500 mulheres) transitando no complexo da Vila Mimosa. Muito embora não se saiba exatamente de onde saiu este número, dado 0 intenso fluxo de pessoas que se pode observar mesmo que assistematicamente, ele não soa inverossímil mesmo ao mais cético dos olhares. Sempre havia pessoas paradas ou caminhando nos corredores, nos estabelecimentos, dançando, algumas comendo em pé ou sentadas nos muros, nas escadas, enfim, sempre uma intensa movimentação de pessoas: as mulheres falavam, caminhavam, dançavam, riam, comiam; os homens conversavam, bebiam, caminhavam pelos corredores, pegavam nas mulheres.

Minha primeira impressão da Vila Mimosa foi uma imensa heterogeneidade que parecia desordenada. No entanto, a pesquisa paulatinamente desconstruiu essa primeira impressão, demonstrando que cada setor e cada atividade têm suas regras, e através delas se constrói a idéia de transitoriedade, tão importante para a compreensão do contexto estudado. Parece mesmo que a Vila é constituída pelo excesso: excesso de barulho, de cheiros, de pessoas, de carros, de voz em volume alto, de gestos. Isso tudo dá ao universo o aspecto de uma tensão contínua e, ao mesmo tempo, de uma dinâmica incontrolável. Certamente que esta é uma pista de reflexão a respeito do lugar e da aceitação ou não dos estrangeiros neste comércio tão diversificado.

\section{Associação: um espaço de poder na Vila Mimosa}

A AMOCAVIM está localizada no segundo andar, sobre a parte central do galpão. Sua sede é dividida em três salas. U ma delas - a maior e mais escondida - foi alugada para um salão de beleza. Assim, a Associação funciona nas outras duas salas: na

\footnotetext{
8 No próximo item demonstrarei o funcionamento da Associação.
} 
Prostituição feminina na Vila Mimosa

primeira delas - um pequeno retângulo - há duas mesas (uma para a presidente e outra para o secretário), algumas cadeiras para os visitantes, uma televisão, dois computadores, um fax e um telefone. A outra sala é menor e comumente fica fechada. Desde que comecei minha pesquisa na Vila Mimosa (em 2002), a pequena sala teve diferentes usos: sala de massagem, do Curso de Informática, palestras, depósito de caixas, para o secretário dormir, um Posto de Atendimento da Caixa Econômica Federal e, depois, do banco Bradesco.

A AMOCAVIM é a entidade que responde pelos acontecimentos sociais, políticos e legais da Vila Mimosa. O discurso de seus integrantes expressa preocupações no que se refere à qualidade de vida das prostitutas na Vila, de forma que elas realizem melhor o exercício da prostituição. A Asso ciação está composta por donas e donos de estabelecimentos de prostituição. Nesse sentido, não é uma associação de prostitutas, é uma "associação empresarial". Portanto, essa preocupação deve ser associada à idéia de que quanto mais e melhor as prostitutas trabalharem maior o lucro. Ao mesmo tempo, há diversos cursos profissionalizantes e cursos de alfabetização para prostitutas, pois também há uma crença de que é preciso proporcionar alternativas de atividades lucrativas para aquelas que não querem permanecer no exercício da prostituição. Resumidamente, as principais metas da AMOCAVIM são: atividades de intervenção ligadas à saúde, à cidadania, à segurança e à educação das prostitutas. Nos últimos anos a Associação tem mantido projetos junto ao Ministério da Saúde com o intuito de compartilhar ensinamentos sobre Doenças Sexualmente Transmissíveis (DSTs) e de distribuir preservativos gratuitamente. Além deste projeto, também há uma parceria com um Banco para o financiamento de um Posto de Saúde e, no começo de 2005, um projeto junto ao Ministério da Cultura e uma ONG norte-americana, capacitando mulheres em situação de 
Elisiane Pasini

prostituição ou moradoras do bairro para a profissão de costureira. ${ }^{9}$

Entretanto, na prática, a resolução de conflitos é o carro chefe da AMOCAVIM. Digo isto por que a principal pauta das conversas na sala da Associação giram em torno de possíveis tentativas de solucionar problemas cotidianos da zona relacionados ao seu andamento, eventuais contratempos junto às prostitutas e aos clientes, organização e discussão com donos de estabelecimentos, gerência das finanças da AMOCAVIM e participação de reuniões com seguranças, traficantes e policiais. Entretanto, a tarefa de resolver esses conflitos não é desempenhada por qualquer pessoa, apenas Graziela - dona de várias casas de prostituição desde a antiga Vila Mimosa, presidente da AMOCAVIM ${ }^{10}$ e uma das principais líderes da Vila Mimosa - tem este poder, afinal, é ela quem responde pelas questões que acontecem no espaço circunscrito da Vila. Além disso, os empreendimentos comerciais e os comerciantes ambulantes, taxistas, enfim, todos os que querem manter uma relação comercial no complexo da Vila Mimosa, precisam de seu consentimento (e pagar uma taxa monetária). Nos últimos tempos, o grupo responsável pela segurança na Vila tem tencionado esse poder e, assim, medido força com a Associação, para autorizar ou não o estabelecimento de outros negócios. Um exemplo foi o consentimento para que o primeiro estrangeiro se tornasse dono de um estabelecimento de prostituição. É certo que esta atitude além de marcar uma disputa velada entre a Associação e o grupo da segurança, também abre uma nova

\footnotetext{
9 Esse projeto tem como principal objetivo resgatar a memória carioca, juntando os temas da prostituição feminina, as escolas de samba e as mulheres de periferia.

${ }^{10}$ Dos sete cargos da diretoria, quatro são desempenhados por mulheres e três, por homens. Ao longo da minha pesquisa, jamais vi ou ouvi falar de alguma reunião da diretoria da Associação. Na prática, a Asso ciação é administrada pela presidente que conta com a ajuda de Tadeu e de Cleuza - que se diz apenas coordenadora de projeto da Vila Mimosa.
} 
Prostituição feminina na Vila Mimosa

etapa, o que muito dos meus informantes chamam "a invasão dos gringos". Os estrangeiros na Vila Mimosa nunca foram bem aceitos. Em diferentes situações vi donos de casa, comerciantes e/ou prostitutas em conflito com eles, não importando quem fosse, bastava apenas falar numa outra língua. Um fragmento das minhas anotações de campo explicita a questão:

Em uma tarde ajudava na organização de um evento que escolheria a Gatinha Mimosa. Naquele momento me encontrava só na sala da Associação, organizando os itens de notas que os jurados usariam para a escolha da "Gatinha". Repentinamente adentra esbaforido e aos berros um homem. Rapidamente o reconheci, era Milton, um dono de estabelecimento mal falado pelos componentes da AMOCAVIM em razão dos vários problemas que provoca quanto ao bom andamento da Vila Mimosa. Milton não deve ter demorado mais do que dois minutos dentro da sala, depois de "gritar" seu problema, virou-se e saiu pisando firme e falando palavras que eu não mais entendia. $\mathrm{Na}$ minha frente Milton esbravejou: Tem um gringo que tá tirando fotos das minhas meninas. É a última vez que venho reclamar, se ele aparecer mais uma vez na minha frente é um homem morto.

Esta é uma das tantas cenas que presenciei o embate de donos de casa que se consideravam verdadeiros donos da zona com aqueles que vinham de fora. Nesse caso específico tratava-se de dois jornalistas alemães que pagaram por uma reportagem so bre a Vila Mimosa. Eles foram alertados que não poderiam tirar fotos. Entretanto, em uma negociação à parte, uma prostituta se permitiu fotografar, só que o jornalista resolveu fazer isso dentro da casa de prostituição de Milton. Mais tarde, como a prostituta havia recebido dinheiro para posar para as fotos, eles foram para um estabelecimento com pouco movimento acompanhado de um membro da Associação, que o defenderia de possíveis confusões. Este exemplo sugere que o embate com os estrangeiros é uma questão que vai além dos muros da AMOCAVIM. Veremos no 
decorrer do artigo que os estrangeiros são também considerados aqueles que podem ser enganados com mais facilidade e isto significa a possibilidade de obtenção de um lucro maior.

Nos últimos anos, o poder de Graziela também tem sido ameaçado a partir do ganho de espaço de Cleuza, responsável pela equipe e pela execução de projetos de intervenção. É ela quem busca o diálogo com entidades, associações, organizações, governo, pesquisadores. O objetivo é tornar a Associação respeitada politicamente e (re)conhecida como um lugar que mantém um trabalho de intervenção sério e competente. No último ano houve contratação de profissionais formados que realizam um trabalho com o objetivo de desmistificar a idéia de que a AMOCAVIM é composta por "cafetinas" - exploradoras da atividade da prostituição -, acusação feita por outros setores sociais, principalmente, ONG's especializadas no tema da prostituição, o que impede a AMOCAVIM de crescer e se estabelecer como uma associação engajada na luta de melhorias para o "mundo da prostituição".

À primeira vista, parece que Cleuza tem mais visibilidade política do que Graziela, no entanto, isso não significa que há mais poder e/ou prestígio. A té por que Graziela, certamente, tem maior respeitabilidade, autoridade e comando na Vila Mimosa, poucas vezes vi uma decisão sua ser questionada. Contudo, nesse jogo pela busca de poder e prestígio, parece-me que as duas mulheres encontraram uma maneira de se mover e, assim, demonstrar valentia. Por conseguinte, de uma forma ou de outra, ambas fortalecem seu lugar na Associação e, ao mesmo tempo, fortalecem a Associação como um instrumento de domínio e de poder o que lhes garante autoridade e prestígio. 
Prostituição feminina na Vila Mimosa

3. Negócios na Vila Mimosa

\subsection{Um negócio de família}

A partir de dados sobre a história de vida de meus informantes, observei que muitos deles estão na Vila Mimosa em razão de um negócio de família. É comum várias pessoas de uma mesma família estarem envolvidas em diferentes negócios na Vila. De todas as histórias que conheci, duas delas são representativas para apresentar meu argumento. Primeiro contarei um pouco da história de Dona Edelvina - mãe de Cleuza, Carina, França, Cassandra, Anita - e, na seqüência, a história de Laerte.

Poucos anos depois de casados, o marido de Dona Edelvina saiu de Campina Grande-PB, onde moravam, para tentar a sorte no Rio de Janeiro. Eles se comunicaram por correspondência durante algum tempo, até que ela ficou cinco meses sem receber notícias do marido. Dona Edelvina, cansada de esperar por notícias, e com o endereço que tinha da última carta do marido foi para o Rio de Janeiro atrás dele, levando consigo seus cinco filhos. No Rio de Janeiro ela o encontrou, estabelecendo residência com ele e seus filhos. Durante os anos seguintes eles tiveram mais cinco filhos. Seu marido se embebedava, a espancava cotidianamente e mantinha relacionamentos com várias mulheres, com quem gastava todo o dinheiro que ganhava. Dona Edelvina decidiu abandoná-lo e, nesta mesma época, começou a costurar para sustentar sua família. Uma de suas freguesas, que era prostituta, Ihe deu a idéia de costurar para as mulheres da zona de prostituição onde trabalhava. Foi costurando que Dona Edelvina conheceu a Zona do Mangue. Alguns anos depois, a senhora monto u uma barraca de lanches onde alguns de seus filhos a ajudavam nos afazeres. A passagem de uma barraca para um estabelecimento de prostituição me foi contada de duas maneiras. $\mathrm{Na}$ história mais difundida, se dizia que um estabelecimento de prostituição fora invadido por bandidos, 0 filho mais velho (já falecido) de Dona Edelvina comprou dessas 
pessoas e o deu a ela. A outra versão, relatada por não familiares, conta que este mesmo filho de Dona Edelvina "invadiu" e tomou para si um estabelecimento de prostituição que pertencia a uma pesso a devedora de uma quantia de dinheiro para ele. Apesar dos diferentes conteúdos das histórias, ambas relatam que Dona Edelvina se tornou uma "dona de casa"11 com a ajuda de seu filho mais velho, ainda na época da Zona do Mangue. Desde o começo de seus negócios na prostituição, a senhora contou com a ajuda de seus filhos, aliás, apenas sua filha mais velha nunca a ajudou, todos os outros filhos já executaram diferentes atividades de trabalho; ainda hoje, alguns deles são proprietários de diferentes comércios: cozinhas, lanchonetes, trailers, casas de prostituição. No começo da pesquisa de campo, seis filhos de Dona Edelvina trabalhavam na Vila Mimosa; atualmente, apenas três estão trabalhando ativamente: elas participam de Projetos de Intervenção na AMOCAVIM e duas delas mantêm outros comércios. Além dessas duas filhas, uma outra, um filho e Dona Edelvina mantêm casas de prostituição alugadas. Logo depois que comecei minha pesquisa de campo, duas filhas de Dona Edelvina se uniram conjugalmente e deixaram seu trabalho na Vila (uma delas ainda recebe uma quantia de dinheiro por alugar seu estabelecimento de prostituição). Além de Dona Edelvina, Dona Felícia, Dona Fátima e Vani também levaram seus filhos para ajudá-las nos seus negócios na prostituição.

A história de vida de Laerte também é representativa na compreensão da maneira como algumas pessoas se tornaram comerciantes na Vila Mimosa.

A mistura do rosto redondo e risonho, o jeito de falar cheio de gírias e com uma musicalidade específica de grupos populares carioca - faz de Laerte um senhor envolvente, e sempre que o encontrava ficava horas ouvindo suas histórias. Laerte é sergipano e foi morar no Rio de Janeiro em 1969. Logo que

11 "Dona de casa" é o temo usado para se referir às mulheres que comandam um estabelecimento de prostituição. 
Prostituição feminina na Vila Mimosa

chegou na cidade conheceu a Zona do Mangue, onde se tornou um cliente assíduo. Laerte estudou até a 5 a série do ensino fundamental, e com a ajuda de conhecidos conseguiu um emprego na Prefeitura Municipal do Rio de J aneiro. Mas, para ele esse emprego não era suficiente para financiar seus sonhos futuros e, aproveitando sua assiduidade e seu bem-estar na antiga Zona do Mangue, abriu um comércio de produtos alimentícios. Naquela época, ele não tinha uma grande quantia de dinheiro para investir em uma casa de prostituição, então comprou um trailer especializado na venda de lanches rápidos. Na montagem da atual Vila Mimosa, Laerte ficou temeroso com os possíveis lucros e optou por investir seu dinheiro (na troca de localização entre as duas zonas) na compra de uma residência para sua família e permaneceu com seu trailer. Atualmente, cerca de quinze anos depois, ele ainda mantém o mesmo trailer, sendo que nos últimos anos o aluga.

A princípio poderia parecer que a história de Laerte seguiria o mesmo caminho que a história de Dona Edelvina, contudo, são histórias bem diferentes. Os filhos de Laerte, diferentemente dos filhos de Dona Edelvina e de outras "donas de casa", são proibidos de freqüentarem a Vila Mimosa. Para esses homens, a Vila não era um espaço para seus familiares se divertirem ou trabalharem. França, por exemplo, que começou desde pequeno a ajudar a mãe nos afazeres de trabalho em zonas de prostituição e, com o passar dos anos, tornou-se dono dos seus próprios negócios, sempre afirmava que seus dois filhos (ainda novos) jamais trabalharão numa zona de prostituição ${ }^{12}$, pois se trata de

${ }^{12}$ França contou que foi obrigado a alugar seu estabelecimento de prostituição que mantém em sociedade com Cleuza - devido às constantes brigas em razão do ciúme da esposa e, também, devido a sua dependência das drogas. $\mathrm{Na}$ segunda gravidez da esposa ela o ameaçou: ou ele deixava de freqüentar a zona ou eles se separavam. França optou por ficar com a esposa e com os filhos. Para ele, a Vila representava ficar dias sem dormir, se relacionar sexualmente com muitas prostitutas, beber e usar drogas, atitudes que não combinavam com a vontade de manter sua família. Atualmente, França tem um pequeno bar/mercado onde vende mantimentos alimentares e bebidas alcoólicas, 
um lugar imoral e repleto de possibilidades de escolhas erradas. No entanto, em ocasiões especiais as esposas podem ser obrigadas a freqüentar a Vila. A esposa de Laerte, por exemplo, foi obrigada a ajudar o marido quando o trailer passou por problemas financeiros e não havia como pagar uma outra pessoa para realizar o trabalho. Assim como Laerte, Alencar afirmou que sua companheira só estava trabalhando em sua lanchonete devido a problemas financeiros. 0 caso de Alencar é ainda mais curioso. Alencar sempre contou que conheceu sua companheira enquanto ela era prostituta e afirmava orgulhosamente que a "tirou" da vida na prostituição. No entanto, ele jamais comentou que ela cuidava da cozinha da sua lanchonete. Apenas em minha última visita na Vila, por acaso, a encontrei no balcão de sua lanchonete conversando com Cleuza. ${ }^{13} \mathrm{~A}$ mulher esbravejava que não suportava ficar trabalhando na cozinha, dizia se sentir prisioneira do marido: "minha vida era um inferno!" Alice contou que quando Alencar a incentivou deixar a atividade da prostituição lhe prometeu casamento e que sua vida seria diferente. Após oito anos juntos ela dizia se sentir tão explorada quanto na época em que se prostituía. Apesar das atuais brigas conjugais, Alice resolveu que não trabalharia mais na cozinha; ficaria no balcão da lanchonete.

\footnotetext{
localizado a alguns passos da sua residência. Sempre soube do dilema de França: uma paixão desenfreada pela vida na prostituição e seu amor pela família. É interessante o uvi-lo falar sobre a falta que sente da vida que levava na "zona", contudo, afirmava ter feito a opção certa, caso contrário, perderia o que para ele é o bem mais precioso: sua família.

${ }^{13}$ A primeira vez que vi Alice - esposa de Alencar - foi durante o Evento Gatinha Mimosa promovido pela AMOCAVIM. Enquanto ajudávamos a organizar o local para o evento, Alencar avisou que eu não deveria me aproximar dele à noite, po is a esposa era muito ciumenta e brava. À noite, Alencar me apresentou sua esposa, entretanto, pouco nos falamos, afinal estava "proibida" de conversar com o casal. Mas, de longe, os observei sempre que possível. Durante todo o evento não os vi dançando, também não vi Alice caminhando no salão, ao contrário de Alencar, que dificilmente permaneceu ao lado da esposa.
} 
Prostituição feminina na Vila Mimosa

Logo me perguntei por que os familiares não podem trabalhar na Vila Mimosa? Ou melhor, por que alguns familiares não podem? Retomando os dados acima é possível observar que há dois modelos deste negócio de família. No primeiro deles, a mãe começou trabalhando em alguma atividade (costureira, vendedora, cozinheira, prostituta) em zonas de prostituição e, atualmente, é dona de um estabelecimento de prostituição e conta com a ajuda de seus filhos. O segundo modelo refere-se aos donos de "casa" que estão sozinhos na Vila: Tadeu, Laerte, Alencar, França, Ângelo, entre tantos outros. Todos esses homens têm filhos (dois deles têm filhos com idade inferior a 10 anos), mas nenhum trouxe ou pensa trazer algum filho para trabalhar consigo na Vila Mimosa. Nos poucos casos em que suas companheiras trabalharam (ou trabalham) na Vila, esta situação é reconhecida como problemática. ${ }^{14}$ À primeira vista poder-se-ia concluir que essa diferença estaria embasada em uma diferenciação sexual: as mulheres trazem seus familiares para trabalhar consigo e os homens não. No entanto, pouco acredito que essa diferença esteja ligada a uma divisão sexual, mas antes, de gênero. Explico-me: noções de masculinidade e feminilidade circulam entre os corpos e, portanto, podem ser alocados em homens ou em mulheres. ${ }^{15}$

\footnotetext{
${ }^{14}$ Também percebi esse mesmo agenciamento em outros contextos estudados. Por exemplo, em Porto Alegre, as prostitutas costumavam ter seus filhos inseridos no negócio da prostituição, ocupando uma função incomum para mulheres: gerenciavam locais de prostituição. Naquele contexto, elas enfatizavam que jamais permitiriam que seus filhos se prostituíssem. 0 proibido era fazer programas. Em São Paulo, também ouvi histórias de mães, tias, primas de minhas informantes que já tinham se prostituído. Entretanto, nenhuma delas comentou a passagem de algum dos seus familiares homens em negócios de prostituição.

${ }^{15}$ Segundo Piscitelli, "Algumas abordagens antropológicas contemporâneas alargam as dimensões consideradas nesse leque de diversidades. Pensando gênero como noções com significados ambíguos e contraditórios, baseadas em domínios, identidades, objetos, comportamentos, e que também se 'impõem' a eles, essas perspectivas rejeitam a idéia de referentes essenciais para as distinções entre características femininas e masculinas. Afirmando que as no çõ es de gênero, incluindo idéias sobre masculinidade e feminilidade, se expressam em metáforas
} 
Entretanto, na nossa sociedade, aparentemente associa-se ao feminino qualidades morais, sentimentais e o cuidado com a família e, ao masculino, o sustento econômico da família. Apesar de trabalharem em uma zona de prostituição essas mulheres cumpriam 0 que se espera socialmente de uma mãe: elas protegiam seus filhos, pois os tinham por perto e, além disso, os sustentavam. Ressalto que todas elas afirmavam que não eram prostitutas, ou seja, eram consideradas mulheres de respeito. Ao mesmo tempo, os homens agenciam bem o principal atributo masculino: sustentavam a família, mas não a traziam para perto de si. Em ambos os casos, o problema é se prostituir e não ganhar dinheiro à custa do trabalho da prostituta. Sendo assim, as pessoas se preocupam em demonstrar publicamente a diferença entre quem se prostitui e quem não o faz.

Entretanto, há uma outra questão importante para analisar. Como já disse, é comum uma pessoa (e sua família) ser dona de vários comércios na Vila. Acredito que isso também venha a se somar no processo de rejeição aos possíveis novos comerciantes estrangeiros. Afinal, a partir da chegada de um deles - pensando na lógica do negócio de família -, rapidamente, muitos outros poderão chegar. De uma certa forma, isso justificava o embate já travado mesmo quando esta situação seja apenas ilusória.

Outro dado de pesquisa interessante é que, na Vila Mimosa, a maioria dos pontos comerciais (casas de prostituição, trailer, lanchonetes...) pertencem a mulheres intituladas de "donas de casas". ${ }^{16}$ Essas mulheres são aquelas que têm como função

cujas raízes e utilizações na vida so cial não são fixas essas abordagens sustentam que tais noções podem ser alocadas, indistinta e/ou simultaneamente, a homens e mulheres". PISCITELLI, Adriana. A Prática feminista e o Conceito de Gênero. In: SCHPun, Mônica R. (org.) Masculinidades. Rio de Janeiro, Boitempo/Edunisc, 2004, p.86.

${ }^{16} \mathrm{Na}$ literatura específica so bre prostituição, percebe-se que os autores apontam uma regularidade no fato de mulheres serem donas de estabelecimentos de prostituição, as famosas "cafetinas". Ver ARIENTE, Marisa A. O Cotidiano da Prostituta em São Paulo: estigma e contradição. Dissertação de Mestrado em Antropologia Social, PUC-São Paulo, 1989; FreitAS, Renan S. Prostitutas, 
Prostituição feminina na Vila Mimosa

enfrentar sujeitos que promovem a desordem nos estabelecimentos, apartar brigas, negociar reivindicações junto às prostitutas e junto à AMOCAVIM, escolher quem trabalha no estabelecimento, controlar os gastos e a venda das bebidas alcoólicas. ${ }^{17}$ Mas, principalmente, é a "dona de casa" quem ocupa uma posição de poder no contexto estudado; é ela quem protege as prostitutas, quem institui as regras de conduta da casa - o que pode e o que não pode fazer -, o estilo de roupas e de sedução das prostitutas e, desta forma, ela é quem se torna a guardiã da moralidade da Vila. Para Moraes (1996), a "dona de casa" é a responsável pelos cuidados com o estabelecimento e, também, quem "define uma relação mais comercial nos negócios da atividade e mais 'profissional' entre estas e as prostitutas".$^{18}$ Assim, é possível haver uma aliança política entre as "donas de casa" e as prostitutas, principalmente quando os assuntos se referem a melhorias de trabalho - construção de creches, realização de cursos, distribuição de preservativos. ${ }^{19} \mathrm{Em}$ se tratando das "donas de casa" também é preciso adentrar na questão sobre a

Caftinas e Policiais: A dialética das ordens opostas. DADOS - Revista de Ciências Sociais, vol. 27, no 2, 1984 e Bordel, Bordéis: negociando identidades. Petrópolis, Vozes, 1985; LeITE, Gabriela S. Eu, Mulher da Vida. Rio de J aneiro, Rosa dos Tempos, 1992; MoRAES, Aparecida F. Mulheres da Vila: prostituição, identidade social e movimento associativo. Petrópolis, Vozes, 1996; SousA, Francisca. O Cliente: o outro lado da prostituição. Fortaleza, AnnaBlume/ Secretaria da Cultura e Desporto, 1998. Parece que a idéia de que são sempre mulheres as que comandam zonas de prostituição é naturalizada. No imaginário social essa idéia é bastante difundida, tanto em novelas como em obras literárias brasileiras. As novelas que apresentam prostíbulos sempre são as mulheres que estão nos seus comandos, foi assim em Roque Santeiro, Renascer, A Indomada e em Porto dos Milagres. Em livros de Jorge Amado como Gabriela, Cravo e Canela, Teresa Batista Cansada de Guerra ou Mar Morto e, em Dona Anja, de J osué Guimarães são sempre mulheres que comandam os prostíbulos.

${ }^{17}$ Algumas dessas funções também são agenciadas pelo(a) gerente da casa, especificamente as questões referentes ao andamento cotidiano da casa; entretanto, está ressaltado de que não se trata da dona.

${ }^{18}$ Moraes, A. F. Mulheres da Vila... Op. cit., p.160.

${ }^{19}$ ID., IB. 
cafetinagem, já que este é um tema recorrente no grupo. Como já disse, alguns grupos especializados no assunto da prostituição acusam a AMOCAVIM de ser um grupo de cafetinas, por este motivo, muitas vezes, o grupo foi impossibilitado de participar de convenções políticas. É certo que as "donas de casa" são comerciantes que têm interesse em lucrar com o negócio da prostituição, mas isso não significa que as mulheres que se encontram em situação de prostituição são vítimas da situação. Ao contrário, há uma linha de compreensão de que é preciso capacitar estas mulheres com afazeres - socialmente reconhecidos como femininos: costurar, limpar, cuidar, etc. - que as possibilitem obter dinheiro de outra maneira. Aqui há uma relação trabalhista em que o patrão lucra com o trabalho do empregado, o que não as difere de qualquer outro tipo de relação de trabalho numa sociedade capitalista. ${ }^{20}$

O número de homens donos de estabelecimento é menor do que o número de mulheres e, além disso, eles parecem influenciar menos nas resoluções de conflitos e gerenciamento da Vila; o departamento dos homens é outro: eles são taxistas e compõem a equipe de segurança. Aqui há uma diferença importante a ser ressaltada: os primeiros problemas em uma casa de prostituição devem ser resolvidos pelo/a encarregado/a daquele turno, somente se este não resolvê-los é que pedirá ajuda a alguém da Associação. Caso Graziela não consiga resolver a situação, os seguranças pagos pela AMOCAVIM serão chamados e, em último caso, a Polícia Militar.

Muito me questionei por que razão haveria mais espaço para as mulheres do que para os homens. Um dos tantos vendedores ambulantes da Vila Mimosa discorreu sobre 0 assunto. Para este homem,

...as mulheres comandam as casas daqui por que são frágeis, os homens estão lá fora, se preocupam e mandam

\footnotetext{
${ }^{20}$ PASINI, E. Homens da Vida... Op. cit.
} 
Prostituição feminina na Vila Mimosa

em coisas mais importantes. Se deixasse tudo com eles [os homens] isso [a Vila Mimosa] ficaria ainda maior. E daí? Onde ficaria a família e a moral da nossa sociedade?

Cleuza acredita que há muitas mulheres donas de estabelecimentos porque elas são pessoas mais fortes e, ao mesmo tempo, sabem lidar melhor com as prostitutas. Entretanto, não são quaisquer mulheres as "donas de casa", mas, sim, mulheres valentes. A valentia tornou-se um atributo de gênero fundamental para esses sujeitos sociais porque há nessa apropriação uma demonstração de força, de ousadia, uma demonstração de poder - na Vila Mimosa se é alguém, se esse alguém tiver domínio, força, autoridade - e, para tanto, é preciso ser valente.

Isto tudo se faz fundamental, porque demonstra a maneira como este macro-espaço de prostituição foi organizado em função das pessoas e do mercado local e, por conseguinte, dá pistas para entender a necessidade da marca da diferença com os estrangeiros que começam a "usar" a Vila Mimosa.

\subsection{A circulação do dinheiro}

Um dos meus primeiros estranhamentos ao conhecer a estrutura de funcionamento da Vila Mimosa foi perceber que 0 negócio da prostituição era apenas um entre tantos outros que ali aconteciam. Ora, sempre achei que uma zona de prostituição teria como único objetivo atender aos consumidores de sexo, mas minha pesquisa de campo demonstrou que a Vila funciona para atender a uma variedade deles: aqueles que desejam comprar bebidas, alimentos, cigarros, drogas, roupas, perfumes, uma infinidade de produtos de consumo. Para refletir sobre o assunto penso na circulação do dinheiro: quanto se ganha, quanto se perde, quando se gasta, quanto se diz ter. Esclareço que meu objetivo nunca foi realizar uma cuidadosa pesquisa etnográfica a respeito de todas as atividades de trabalho que compõem o universo estudado, mas, antes, olhá-las com 0 intuito de compreender como o comércio da prostituição - e aquele que se 
dá no entorno dele - é estruturado: quanto custa o que se vende na Vila Mimosa? Afinal, o fenômeno da prostituição também deve ser analisado pelo aspecto econômico, visto que envolve, emprega e sustenta um número significativo de pessoas. ${ }^{21}$

$\mathrm{Na}$ Vila Mimosa, assim como em outros universos da prostituição estudados ${ }^{22}$, havia uma diferenciação entre as atividades de trabalho que compunham seu cenário: quem desempenha uma ou outra atividade será tratado, falado, olhado de uma ou de outra maneira. Assim, construí uma pirâmide hierárquica imaginária que, além de demonstrar essa lógica de valores do agenciamento das atividades, também apresenta semelhanças e desigualdades entre as atividades de trabalho e, com isso, explicita a pluralidade e a especificidade na estrutura e na consolidação dos serviços prestados na, e para a, zona. Dividi as categorias de atividades de trabalho em cinco grandes grupos: os proprietários de estabelecimentos de prostituição, os trabalhadores da AMOCAVIM e aqueles que prestam serviços na, e

\footnotetext{
${ }^{21} \mathrm{O}$ número de pessoas que trabalham no mercado prostitucional é incontável, entretanto, segundo Leonini, a atividade ocupa o terceiro lugar, depois do comércio de armas e de drogas dentro os negócios ilegais mais rentáveis, de acordo com as estimativas da ONU. Inclusive, por esses motivos a autora afirma que o exercício da prostituição deveria ser entendido como um fenômeno de massa. LEONINI, Luisa. Os Clientes das Prostitutas - Algumas reflexões a resp eito de uma pesquisa sobre a prostituição em Milão. In: SCHPUN, Mônica R. (org.) Masculinidades. Op. cit.

${ }^{22}$ Ver maio res detalhes em PASINI, Elisiane. "Corpos em Evidência", pontos em ruas, mundos em pontos: a prostituição na região da Rua Augusta em São Paulo. Dissertação de Mestrado em Antropologia Social, IFCH/Unicamp, Campinas, 2000; O uso do preservativo no cotidiano de prostitutas em ruas centrais de Porto Alegre. In: Benedetti, Marcos e FÁbregas-Martinez, Ana. (orgs.) $\mathrm{Na}$ batalha: Identidade, Sexualidade e Poder no Universo da Prostituição. Porto Alegre, Dacasa/Palmarinca, 2000; Limites Simbólicos Corporais na prostituição feminina. Cademos Pagu, $\mathrm{n}^{\circ}$ 14, 2000; Fronteiras da intimidade: uso de preservativo entre prostitutas de rua. In: BRUSCHINI, Cristina e PINTO, Celi. (orgs.) Tempos e Lugares de Gênero. São Paulo, Editora 34, 2001; Prostituição e Diferenças Sociais. In: AlmeIDA, Heloisa B. et alii. (orgs.) Gênero em Matizes. Bragança Paulista, Coleção Estudos CDAPH, 2002.
} 
Prostituição feminina na Vila Mimosa

para a, Vila (professores, palestrantes, pesquisadores, entre outros), os proprietários de outros tipos de estabelecimentos, os empregados em geral e, finalmente, as prostitutas e os clientes.

Entretanto, interessa neste artigo ver como é consolidada a organização econômica na Vila Mimosa. Ser dono de uma casa de prostituição parece ser o grande sonho da maioria dos meus informantes - gerentes, prostitutas, ou mesmo, taxistas. ${ }^{23}$ Certamente, essa busca está envolvida pelo desejado sucesso financeiro tão comentado por todos. Inclusive, como já foi visto, essa seria a categoria do topo da tal escala hierárquica. A propaganda que os donos fazem de suas "casas" é intensa, entretanto, a exaltação de ter uma "casa" de prostituição nem sempre passa pela contagem do lucro do negócio. Parece até que estes comerciantes pouco se preocupam (ou sabem) com esse lucro. Diversas vezes perguntei sobre algum tipo de controle das despesas e dos lucros, e obtinha como respostas que eles apenas sabiam do controle do número de bebidas vendidas e do número de programas feitos. ${ }^{24} \mathrm{Na}$ maioria das vezes, 0 dono do estabelecimento não era capaz de dizer quantas prostitutas faziam parte do grupo de mulheres que trabalhavam em seu estabelecimento, apenas estimavam um número, isso se dá em

\footnotetext{
${ }^{23}$ A amostra da pesquisa foi formada por quarenta e cinco pessoas: seis clientes, três prostitutas, sete donos e dez donas de estabelecimentos (não necessariamente apenas de prostituição), cinco gerentes de estabelecimentos de prostituição, dois funcionários da AMOCAVIM, duas funcionárias do salão de beleza, um massagista do salão de beleza, uma cozinheira, dois taxistas, do is vendedores ambulantes e quatro companheiras de do nos de estabelecimentos.

${ }^{24} \mathrm{O}$ comum é em cada turno do dia um novo gerente assumir a "casa" e sua primeira tarefa é indicar em um caderno quantas cervejas havia no estoque. Quando o novo gerente confere o número de cervejas no estoque ele obtém 0 número de cervejas do tumo anterior. A partir desta diferença é que é sabido o número das cervejas vendidas. Em relação ao número de programas feito há um outro caderno com o nome de cada prostituta em que é assinalado com um risco cada vez que ela faz um programa. 0 dinheiro dos quartos usados fica em uma caixa separado do dinheiro obtido pela venda das bebidas. Mas, to do o dinheiro recebido na "casa" é da responsabilidade de quem a está gerenciando naquele turno.
} 
razão da circulação de prostituição entre os estabelecimentos 0 que, aliás, gera conflito entre os donos que não gostam deste trânsito, pois despersonaliza o estabelecimento. Tadeu, que parecia organizado e interessado em mostrar aos outros esta imagem de um bom comerciante, jamais falou em números do lucro com o comércio com a prostituição. Fernanda foi categórica ao me explicar que não se preocupava em quanto ganhou ou quanto gastou, mas antes em pagar suas contas e da sua família. Observei que "donas/os de casa", quando precisavam pagar suas contas, repassavam a responsabilidade para os "funcionários" (prostitutas e gerentes) e os incitavam a fazer com que os freqüentadores gastassem mais dinheiro com bebidas e com os quartos de programas. Esse mesmo discurso estava presente nas falas das prostitutas em minhas outras pesquisas. Elas afirmavam que quando tinham uma conta para pagar tentavam fazer mais programas naquele dia, caso contrário, não "batalhariam" com tanto afinco ou, dependendo do caso, nem "batalhariam".

Talvez meus informantes não quisessem falar do lucro de seus negócios na prostituição por desconfiarem do outro - não exatamente da minha pessoa -, pois diversas vezes eles comentaram sobre o medo de serem explorados. Havia sempre no ar um receio de que o outro pudesse enganá-lo e, por isso, também era presente 0 discurso da esperteza: usa-se do atributo da valentia, não se conta todos os segredos para o outro, não se conta dinheiro na frente de outras pessoas, não se paga muitas bebidas, enfim, uma variedade de práticas. Porém, aqui há um limite fundamental que faz parte da publicização da esperteza: é preciso mostrar aos outros que se é uma pessoa bem sucedida, mas não pode se deixar explorar, enganar.

$\mathrm{Na}$ Vila Mimosa o ganho do dinheiro e a sua publicização é fundamental para se constituir um sujeito de poder. Na maioria das vezes, a publicização desse dinheiro é feita através do provimento a uma mulher, do investimento em melhorias no estabelecimento, da utilização de jóias, da compra de carros, entre outros. Contudo, não são todas as atividades de trabalho que 
Prostituição feminina na Vila Mimosa

proporcionam aos sujeitos essa posição. Dessa forma, mais do que a intenção de ter um estabelecimento de prostituição, se quer ter 0 poder e ocupar a posição social que um dono de estabelecimento de prostituição ocupa. Por outro lado, a prostituta não é quem recebe menos dinheiro na Vila, entretanto, é a atividade mais desvalorizada. Certamente, não é porque ela realize os desejos dos homens, mas talvez porque seja ela quem explicite que se trata de um negócio da prostituição. Em outras palavras, é a prostituta quem abstrai a qualidade de romance e intimidade na relação com o homem para torná-la um serviço prestado. Com isso quero afirmar que fica a cargo da prostituta explicitar o mercado da prostituição: ela oferece um serviço específico e o vende (o serviço, não o corpo). Aqui, menos do que o valor real do lucro que se tem com o negócio da prostituição, na Vila o poder simbólico dá aos agentes o lugar de sujeito social.

\subsection{0 jogo da ilegalidade/legalidade}

Numa das tantas tardes que passei com Fernanda em seu estabelecimento, vi França chegar e, depois dele ter ficado um pequeno intervalo de tempo na AMOCAVIM, veio conversar conosco. França é um dos irmãos de Cleuza e Carina, o qual, naquele período da pesquisa estava afastado do seu negócio na Vila Mimosa. Apesar dos nossos questionamentos sobre o motivo que o levava ali, França permaneceu comedido e evasivo em suas respostas. Nas conversas discretas que manteve com Cleuza, percebi que França esperava por uma pessoa e por um documento. Pouco tempo depois fui apresentada a Sônia, uma famosa dona de estabelecimento de prostituição que também estava afastada do negócio na Vila. França esperava Sônia. Cleuza contou que França esperava sua assinatura, de Graziela e de Sônia, para que as três mulheres fossem avalistas em um contrato de locação. Levei muitos dias para entender a ligação destas mulheres entre si e, também, a razão delas se tornarem avalistas conjuntamente. Cleuza, Graziela e Sônia - três donas de estabelecimentos de prostituição - são as proprietárias legais do 
galpão da Vila Mimosa - o que Ihes dá o direito de ser fiadoras. Retomo esta situação etnográfica para mostrar um elemento fundamental na compreensão do complexo empresarial chamado Vila Mimosa.

Para a legislação brasileira, manter um estabelecimento de prostituição é considerado crime, portanto, a Vila Mimosa é um negócio ilícito. Então, como um negócio ilícito poderia ser uma garantia de um negócio lícito? Além disso, como já anunciei, a AMOCAVIM mantém projetos em parceria com órgãos públicos e legais: Prefeitura Municipal, Ministério da Saúde, Igrejas, ONGs. Ora, se o complexo da Vila Mimosa é um negócio ilegal, como pode estabelecer uma negociação com órgãos e entidades legais? Também questiono como a Associação pode pagar imposto pelas casas de prostituição, sendo que este é um dever legal? Curiosa com essas questões busquei compreender como a Vila Mimosa é constituída legalmente.

No contrato legal da Vila está especificado que o galpão é um empreendimento comercial sem explicitar seu uso. J á as casas de prostituição localizadas em frente ao galpão são antigas moradias que foram transformadas em empreendimentos comerciais. Cada um desses bares funciona com seu registro legal de comércio. Como já foi dito, os estabelecimentos localizados do outro lado da rua foram comprados separadamente ${ }^{25}$, cada dono é responsável por suas contas e a maioria deles não está associada à AMOCAVIM, mesmo que esta se sinta responsável por todos os estabelecimentos (de prostituição ou não). A Vila Mimosa funciona como um complexo comercial e, assim, mantém seus direitos e deveres como qualquer outro empreendimento do mesmo tipo. Dessa forma, o imóvel tem seus deveres legais, como o pagamento de impostos, energia elétrica, abastecimento de água e saneamento, entre outros, em contrapartida, recebe os serviços

\footnotetext{
${ }^{25}$ Por exemplo, um dos estabelecimentos que fica do lado contrário do galpão é uma antiga residência da família de um dos seus sócios (funcionário da Prefeitura Municipal) que, depois da morte dos pais, a transfomou em um estabelecimento de prostituição.
} 
Prostituição feminina na Vila Mimosa

de limpeza, água, esgoto. ${ }^{26}$ As três mulheres citadas são proprietárias legais da Vila, ou seja, os estabelecimentos de prostituição, legalmente, não pertencem aos auto-intitulados donos, os quais têm apenas um documento onde consta que 0 estabelecimento de prostituição lhes pertence, o que só tem valor dentro da Vila, e nenhuma validade legal.

No Brasil, o ato de prostituir-se não é crime, entretanto, to do o mercado no entorno da prostituta é considerado uma contravenção. Certamente, nessa questão há elementos fundamentais para compreender o lugar desses sujeitos no "mundo" da prostituição. Além disso, as últimas tentativas da legalização da atividade no país continuam tendo como base um olhar em que a prostituta desempenha uma função conhecida como o "mal necessário", quase sempre como se a prostituta permanecesse sendo a vítima de um sistema econômico opressor.

Contudo, interessa aqui entender como um lugar específico de comércio sexual é organizado, apesar de ser compreendido como ilegal. ${ }^{27}$ Arrisco a afirmar que se trata justamente de um descaso e hipocrisia social que insistem em deixar de lado questões sobre a moralidade e a sexualidade. Essa discussão nos faz perceber que a atividade da prostituição requer um olhar

\footnotetext{
${ }^{26} \mathrm{O}$ valor do IPTU e do abastecimento da água são divididos entre todos oS estabelecimentos que estão dentro do galpão principal e a conta de energia elétrica é paga separadamente por cada dono de estabelecimento.

${ }^{27}$ Segundo o Código Penal (1977), capítulo V, é crime: “Induzir alguém a satisfazer a lascívia de outrem" (art 227); "Induzir ou atrair alguém à prostituição, facilita-la ou impedir que alguém a abandone" (art. 228); "Manter, por conta própria ou de terceiro, casa de prostituição ou lugar destinado a encontros para fim libidinoso, haja, ou não, intuito de lucro ou mediação direta do proprietário ou gerente" (art. 229); "Tirar proveito da prostituição alheia, participando diretamente de seus lucros ou fazendo-se sustentar, no todo ou em parte, por quem a exerça" (art. 230); "Promover ou facilitar a entrada, no território nacional, de mulher que nele venha exercer a prostituição, ou a saída de mulher que vá exercê-la no estrangeiro" (art. 231). A lei não proíbe a troca de sexo por dinheiro. Ver também HungriA, Nelson. Comentários ao Código Penal. Revista Forense, vol. VIII, Rio de J aneiro, 1947.
} 
cuidadoso e um debate em que a sociedade enfrente a questão como uma prática social. É preciso trazer os sujeitos em situação de prostituição para junto do debate e da compreensão e, assim, propor a possibilidade da mudança social.

\section{A circulação dos freqüentadores}

Pesquisas etnográficas anteriores, realizadas em diferentes contextos de prostituição feminina, e a literatura especializada sobre o tema revelam a importância dos clientes ${ }^{28}$ como parte constitutiva do universo da prostituição, apesar disso, estes sujeitos são pouco conhecidos. Imbuída da curiosidade deste desconhecimento fui levada a investigar quem são estes sujeitos consumidores de sexo, o "outro" da relação da prostituição. Nas primeiras incursões ao campo uma questão se impôs: circunscrever 0 universo de pesquisa na categoria clientes era demasiado limitado para dar conta da riqueza e da complexidade que envolvia os homens naquele contexto de prostituição. A procura por relações sexuais é uma, e nem de longe a principal, dentre inúmeras razões que levam esses homens a Vila Mimosa. Para dar conta dessa complexidade, utilizei a categoria "homens freqüentadores", que engloba a multiplicidade dos laços desses diferentes homens com a Vila Mimosa: sociabilidade, trabalho, relações sexuais. Enfim, uma variedade de motivos que vão além da realização de encontros sexuais com prostitutas.

\footnotetext{
${ }^{28}$ Entendo por "clientes" os homens com os quais as "prostitutas" mantêm relações sexuais no contexto da prostituição, caracterizadas principalmente pela troca de um serviço (o contato sexual) por um bem (dinheiro, entre outras coisas). Apesar da possibilidade de uma ampliação do espectro de possíveis trocas entre as prostitutas e os clientes, isso não as equipara às relações com os não clientes. Essas últimas são entendidas como aquelas em que são trocados sentimentos de afeto e de fidelidade e, principalmente, não acontecem nos locais de prostituição.
} 
Prostituição feminina na Vila Mimosa

$\mathrm{Na}$ Vila Mimosa, muitos freqüentadores não se consideravam clientes ${ }^{29}$, apesar de se relacionarem sexualmente com prostitutas. Confesso que apenas depois de muita convivência compreendi a lógica desta afirmação. Isso acontecia por dois fortes motivos. 0 primeiro deles porque esses homens transgrediam três regras que constituem 0 agenciamento da atividade da prostituição: não pagavam para se relacionar sexualmente com uma prostituta (quando muito fazem uma troca de favores); permaneciam por um tempo indeterminado junto a elas nos quartos de programa; e, principalmente, eram tratados de forma diferente daqueles freqüentadores que eram usuários "apenas" de programas, recebiam "privilégios" da prostituta quando ela deixa de cumprir algumas regras que a constitui enquanto profissional, como não beijar, não dormir, não gozar, usar preservativo masculino e cobrar o programa. 0 segundo era que ser um cliente era um motivo de chacota entre os outros homens. Para o homem, não ser tratado como um cliente era motivo de orgulho e satisfação, afinal, "cliente não é homem", ou seja, é preciso se mostrar diferente daquele freqüentador que obedece as regras da zona e, por isso, é menos valorizado. Cliente é o homem que paga pelos serviços sexuais, paga mais pelos produtos oferecidos na Vila, paga bebidas e presentes para as prostitutas, não recebe a mesma performance sexual das prostitutas quando comparado aos não-clientes, é maltratado pelos outros homens e, ainda, é entendido como um não homem - aqui lê-se não masculino. Isso tudo me levou a concluir que o

\footnotetext{
${ }^{29}$ Entendo por clientes os homens consumidores de relações sexuais oferecidas no exercício da prostituição. São relaçõ es que só ocorrem mediante pagamento e no período do programa. Apesar da possibilidade de uma ampliação do espectro de possíveis trocas entre as prostitutas e os clientes, isso não as equipara às relações com os não clientes - as parcerias afetivas em que são trocados sentimentos de afeto e de fidelidade. Nesse tipo de relação, as prostitutas podem realizar seus desejos sexuais e não se preocupar com as regras que definem uma boa profissional, sem esquecer que tais relações não acontecem em locais de prostituição e não são pagas.
} 
cliente da Vila Mimosa é a figura menos valorizada, no entanto, é ele quem constitui a relação da prostituição e, portanto, é quem constitui o negócio da Vila Mimosa.

Aqui há uma especificidade que deve ser lembrada. Apesar dos clientes serem menos valorizados, assim como os estrangeiros, o cliente estrangeiro é deveras valorizado pelas prostitutas. Tânia, uma prostituta que acabara de voltar de uma temporada de trabalho em diversos países da Europa, me chamou a atenção para essa questão. Sempre que tinha uma oportunidade, Tânia comparava os homens brasileiros com os alemães (país onde mais permaneceu):

Aqui no Brasil eles pechincham e maltratam as prostitutas. Os alemães não, eles pagavam os programas com satisfação, felizes, muito diferente dos brasileiros que sempre reclamam. Não é só porque eles são mais ricos. Tenho muito cliente aqui [no Brasil] bem ricão. É uma questão cultural, os homens respeitam mais as mulheres naquele país.

Tânia foi presa por estar ilegalmente no país e o dinheiro que juntou na temporada fora do Brasil foi apreendido. Ela dizia que estava na Vila Mimosa apenas para juntar uma nova quantia de dinheiro para retornar a Alemanha. Parece que o cliente estrangeiro oferece uma maior probabilidade de the proporcionar uma outra vida.

À guisa de conclusão

Mesmo brevemente, como foi visto, as narrativas locais apontam para a circulação de estrangeiros no contexto da Vila Mimosa, primeiro como meros usuários da "zona" e, nos últimos tempos, como donos de casas de prostituição, o que acaba por reafirmar que os mesmos utilizam a estrutura de prostituição montada para o consumo local. 
Prostituição feminina na Vila Mimosa

Sempre que os informantes colocavam a presença de estrangeiros na Vila Mimosa ela aparecia como uma possível possibilidade de tirar vantagem. Por exemplo, uma carteira de cigarros de uma marca estrangeira - produto reconhecido como especialmente do gosto dos freqüentadores estrangeiros -, em qualquer estabelecimento não custa mais do que $R \$ 5,00$, na Vila é vendida por $R \$ 12,00$ ou $R \$ 1,00$ cada cigarro (valor de abril de 2005). As prostitutas, quando percebiam que seu possível cliente era um estrangeiro, imediatamente aumentavam 0 valor do programa ou o valor das práticas sexuais realizadas. Ou então, contavam histórias ainda mais envolventes a respeito do seu sofrimento e de sua falta de recursos financeiros com o intuito de obter maior lucro a dita e reconhecida ingenuidade dos clientes estrangeiros. A Associação, ao ser procurada por algum profissional (entidades, associações, televisões, jornais, revistas, entre outros) para alguma reportagem e/ou estudo, pede em troca algum benefício, que pode ser dinheiro ou benfeitorias em termos simbólicos, no entanto, ao se tratar de estrangeiros, esta regra torna-se obrigatória e os valores em dinheiro sofrem um aumento de até $100 \%$.

As práticas nesse contexto são agenciadas por uma série de regras. Lembro da primeira vez que uma pessoa estranha sentouse ao meu lado e, repentinamente, indagou-me sobre a pesquisa. Entendi que as informações na Vila circulavam rapidamente, havia um forte controle do grupo em relação ao "outro". Logo percebi que regras de conduta estavam em todos os lugares, valores, visões de mundo, agenciamentos de práticas sociais. Para ser uma prostituta, um cliente, um freqüentador, um privilegiado, uma "dona de casa" - categorias empíricas do campo estudado era preciso ter um tipo de prática ordenada pela visão de mundo daquele grupo. A Vila Mimosa é um universo de valores específicos que informam as práticas sociais daquele contexto.

Certamente, penso em regras de conduta que nem sempre são ditas e/ou explicitadas, ainda que muitas delas o sejam sobretudo aquelas que informam a conduta dos principais agentes 
da atividade da prostituição: prostituta e cliente. Contudo, há uma série delas que pertencem apenas à prática dos sujeitos. A convivência com as pessoas permitiu que eu compreendesse a existência de um sistema de comportamento, que deve ser obedecido para que a Vila se constitua enquanto um espaço de moralidade, inclusive, tendo as "donas de casa" como guardiãs desses atributos morais. Refiro-me às regras que controlam o que é permitido ou não no universo da Vila. Ao mesmo tempo, há as que só serão agenciadas em momentos ímpares, quando é preciso retomar algum valor moral que foi "perdido" no descumprimento de alguma regra. Segundo Malinowski ${ }^{30}$, há casos - como do exemplo que contou em que houve a quebra da exogamia - que conseguem se manter às escondidas e, assim, não há problema algum no desenrolar da história, mesmo que o acontecimento signifique uma quebra de conduta. 0 problema é quando esta se torna pública; aqui, a necessidade de castigo visa restabelecer a moral do grupo. Salvaguardo as diferenças, na Vila, esse tipo de descumprimento das regras também acontece: quando um cliente não se comporta como deveria, quando uma prostituta transita em casas sem a permissão, quando há roubos, quando uma esposa demonstra ciúme sem ter legitimidade para isso, quando um homem não defende sua honra, quando um freqüentador não protege uma mulher, entre outras. Esse tipo de conduta obriga o grupo a reestruturar suas práticas. Quando problemas cotidianos da Vila não são resolvidos facilmente, são organizadas pequenas reuniões entre algumas pessoas concebidas e reconhecidas pelo grupo como portadores de poder.

Retomo uma das conversas com Cleuza, que apresentei no começo do artigo, na qual ela contava sobre os problemas que 0 "gringo" tem causado à Vila, ao trazer à tona a disputa com 0 grupo de seguranças, apresentar uma casa de prostitutas mais

\footnotetext{
30 Malinowski, Bronislaw. Crime e Costume na Sociedade Selvagem. São Paulo, Editora UNB, 2003.
} 
Prostituição feminina na Vila Mimosa

so fisticada quando comparadas ao to do da Vila Mimosa e, mais, ao criar para si um grupo seletivo de freqüentadores. Segundo Cleuza, todas as noites o alemão aluga uma Van que circula pelos hotéis e pelo calçadão de Copacabana e traz os estrangeiros para a Vila Mimosa. Todavia, estes homens não podem transitar pela "zona" como um todo, eles devem permanecer apenas na "casa" do alemão.

Em um material consultado na internet ${ }^{31}$, em que estrangeiros trocam mensagens a respeito de locais de prostituição no Rio de J aneiro, há uma visão inferiorizada desses homens sobre a Vila Mimosa: as mulheres são feias, o lugar é sujo e feio. No entanto, a Vila ainda é uma forte referência de prostituição na cidade. Talvez em função desse olhar é que o representante desses estrangeiros tente construir um outro espaço, numa tentativa de diferenciar-se da Vila como um todo, mas, ao mesmo tempo, permanecendo neste lugar. Não permitir o trânsito de seus clientes por toda a zona é um dado fundamental nesse argumento. Parece mesmo, que há uma tentativa de marcar a diferença entre sua casa de prostituição e o resto da Vila Mimosa.

É certo que essa é uma marca de diferenciação criada pelo proprietário e, além disso, é uma forma de propor uma outra maneira de organizar a dinâmica da Vila Mimosa. Afinal, que lugar esses estrangeiros poderão ocupar na Vila no futuro? Mesmo que esse lugar ainda esteja em construção, ele já demonstra conflitos.

\footnotetext{
${ }^{31}$ Este material pertence a Adriana Piscitelli e é relativo ao projeto "Paisagens sexuais: Imagens do Brasil no marco do Turismo Internacional".
} 